\title{
Educação Especial em Sassari (Itália) e em Vitória (ES, Brasil): uma pesquisa comparada
}

\author{
Denise Meyrelles de Jesus ${ }^{1}$ \\ ORCID: 0000-0001-7966-5424 \\ Alexandro Braga Vieira ${ }^{1}$ \\ ORCID: 0000-0001-5952-0738 \\ Lorrayne Hewellen Cristino Ribeiro ${ }^{1}$ \\ ORCID: 0000-0002-6700-5434 \\ Renata Santos Venturini ${ }^{1}$ \\ ORCID: 0000-0002-8934-5210
}

\section{Resumo}

0 estudo objetiva compreender interseções entre as políticas de inclusão escolar/Educação Especial de Sassari (Itália) e Vitória (ES, Brasil), tendo como fundamentação teórica os pressupostos da pesquisa comparada em Educação e as contribuições provindas de teóricos do campo da Educação/Educação Especial. Tal objetivo emerge da necessidade de desvelar como ocorrem os movimentos de constituição de escolas comuns em espaços-tempos inclusivos no contexto educacional apresentado por diferentes sociedades. A coleta de dados ocorreu por meio de grupos focais com profissionais que atuam tanto com estudantes com necessidades educacionais especiais matriculados em escolas italianas, quanto com docentes brasileiros do atendimento educacional especializado que articulam ações nas escolas comuns para a inclusão de estudantes com deficiência, transtornos globais do desenvolvimento e altas-habilidades/superdotação. Como resultados finais, o estudo evidencia que acordos internacionais impulsionaram as realidades investigadas a compor cenários escolares mais inclusivos por meio de várias políticas públicas educacionais e que a realidade italiana e a brasileira podem aprender em diálogo uma com a outra. Afinal, considerando as diferenças históricas, econômicas, políticas, estruturais e educacionais, podemos dizer que há avanços quanto à matrícula dos estudantes na escola comum, à composição de redes de apoio para que eles permaneçam e a um conjunto de preocupações e tentativas para garantir o acesso ao conhecimento sistematizado.

\section{Palavras-chave}

Educação Especial - Pesquisa comparada - Políticas educacionais.

1- Universidade Federal do Espírito Santo, Vitória, Espírito Santo, Brasil. Contatos: jesusdenise@hotmail.com, allexbraga@hotmail.com, lorrayne.hewellen@hotmail.com, renatickaventurini@gmail.com. 


\section{Special Education in Sassari (Italy) and Vitória (ES, Brazil): a comparative study}

\section{Abstract}

The study aims to understand the intersections between the policies of school inclusion/ Special Education in Sassari (Italy) and Vitoria (ES, Brazil), the theoretical framework being the assumptions of comparative research in education and the contributions coming from Education/Special Education theorists. This objective derives from the need to unveil how the movements of opening up inclusive space-time in regular schools within the educational context are conducted in different societies. Data collection was obtained through focus groups with both special educational professionals in Italian schools and Brazilian teachers of Specialized Education Service. The latter are those who articulate actions in regular schools intended to include students with disabilities, pervasive developmental disorders, and high skills/giftedness. As final results, the study shows that international agreements have driven the realities investigated to compose more inclusive school scenarios through various educational public policies and that the Italian and Brazilian reality can learn from each other. After all, considering the historical, economic, political, structural and educational differences, it can be argued that there are advances concerning the enrollment of students in the regular schools; the setup of support networks to prevent drop-out; and a set of concerns and attempts to guarantee the access to systematized knowledge.

\section{Keywords}

Special Education - Comparative research - Educational policies.

\section{Introdução}

A constituição das escolas comuns em espaços-tempos inclusivos vem sendo perseguida por diferentes países, devido ao fato de reconhecerem a diferença como condição intrínseca/constitutiva dos humanos e a apropriação do conhecimento como inter-relação entre sujeitos que trazem trajetórias, saberes, linhas de raciocínio diversas, além de demandas de aprendizagem comuns e específicas.

Esse reconhecimento é impulsionado por um conjunto de acordos internacionais que ganhou maior sustentação nos anos 1990, quando diferentes nações põem em análise o quanto o acesso à educação formal se mostrava possivel para uma pequena parcela da população, enquanto se mostrava restritivo e impiedosamente fechado para grande parte. Os acordos internacionais firmados resultaram, por exemplo, na Declaração Mundial de Educação para Todos e na Declaração de Salamanca, quando se constata que, no início 
da década de 1990, havia uma parte da população sem apropriação de conhecimentos e habilidades essenciais para a vida em sociedade (UNESCO, 1990).

A análise crítica dessa realidade levou diferentes países a traçaram um conjunto de objetivos comuns para satisfazer às necessidades básicas de aprendizagem de todos, culminando na defesa por escolas mais inclusivas, que implicam espaços-tempos comprometidos com o desenvolvimento de outras pedagogias (ARROYO, 2014), ou seja, pedagogias que reconhecem a diferença como potência humana e os sujeitos escolares como históricos, sociais e capazes de aprender, incluindo as pessoas que possuem desvantagens severas. Diante disso, motivamo-nos a entender como diferentes nações do mundo compõem políticas para a garantia do direito à educação de todos, respeitando as singularidades de cada sujeito ou grupo de sujeitos, e como as unidades escolares põem em ação as políticas instituídas.

Dessa forma, compusemos um estudo comparado, envolvendo grupos de pesquisa de três universidades brasileiras. Por meio de um regime de internacionalização com universidades e profissionais da Educação Básica de países estrangeiros, busca-se compreender como diferentes países (México, Itália, Moçambique) vêm implementando políticas de inclusão escolar/Educação Especial, a fim de dialogar com as constituídas em alguns cenários brasileiros. Neste momento, problematizamos as relações existentes entre as políticas de Educação Especial/inclusão escolar de Sassari (Itália) e as de Vitória (ES, Brasil).

Nossos eixos de estudo, nesses territórios, recaem sobre a concepção de inclusão; as redes de apoio; os profissionais e suas respectivas formações; as práticas organizativas da/na escola, envolvendo o planejamento, o trabalho pedagógico e a avaliação. Assim, buscamos destacar as políticas de inclusão escolar voltadas à escolarização de sujeitos denominados, à moda brasileira, pessoas com deficiência, transtornos globais do desenvolvimento e altas habilidades/superdotação (BRASIL, 2008), e, à moda italiana, pessoas com necessidades educacionais especiais. Para a composição desse processo de tradução ${ }^{2}$ (SANTOS, 2008), dialogamos primeiramente com os pressupostos da pesquisa comparada em educação e apresentamos o caminho teórico-metodológico constituído para a realização do estudo. Em seguida, realizamos diálogos entre as políticas de Educação Especial, em uma perspectiva inclusiva, constituídas em Sassari e as implementadas no cenário brasileiro (Vitória).

\section{Pressupostos teórico-metodológicos para a tradução de Sassari em Vitória, e de Vitória em Sassari}

Produções recentes brasileiras e internacionais evidenciam grandes movimentos sociais, políticos e educacionais em torno de uma proposta mais inclusiva de educação, assumindo o princípio da educação de todos (BRASIL, 2008; BANCO MUNDIAL, 2012). Com base no atual contexto de globalização, destaca-se, então, a pertinência do estudo comparado internacional sobre as especificidades da gênese e do desenvolvimento da escola universalizada em diferentes países, possibilitando a produção de conhecimentos

2- Santos (2008) conceitua tradução como um processo de fazer dialogar determinadas realidades para captar pontos de contato e singularidades, sem perder de vista a diversidade. 
sobre as maneiras pelas quais a escola para todos vem alcançando legitimidade em âmbito mundial (NÓVOA; CATANI, 2000).

A comparação em Educação não se configura como um tema contemporâneo, tampouco como um movimento exclusivo de uma área de conhecimento (MARCONDES, 2005). Percebe-se que, historicamente, o diálogo com novos referenciais teóricos e metodológicos do campo da História e da Antropologia provocou o distanciamento dos estudos comparados de uma perspectiva tradicional e homogeneizadora fundamentada na abordagem positivista/funcionalista. Tal movimento permitiu a criação de um novo quadro conceitual, por meio do qual se abre a possibilidade de lançar um olhar outro sobre fenômenos a serem analisados, destacando seus traços genuinamente particulares (REZENDE; ISOBE; MOREIRA, 2013).

Franco (2000) afirma que, nos processos de comparação, temos um outro como ponto de análise e simultaneamente somos o outro de alguém. Trata-se do reconhecimento do outro e de si mesmo por intermédio do outro. Apesar da significativa gama de pesquisas desenvolvidas em âmbito nacional a respeito da história das conquistas sociais da pessoa com deficiência, transtornos globais do desenvolvimento e altas habilidades/superdotação, percebe-se, no Brasil, que a produção científica com relação à Educação Especial, em nível de estudo comparado internacional, ainda é tímida. Portanto, acreditamos ser de extrema importância

[...] conhecer e compreender as experiências educacionais em países e/ou sociedades, próximos ou distantes entre si, no tempo e no espaço, a fim de cartografar o processo crescente de especialização do conhecimento e suas implicações para as práticas pedagógicas com estudantes com deficiência. Além disso, compreender como os discursos pedagógicos foram produzidos e produziram noções específicas de estudante, de escolarização, de aprendizagem e de deficiência em cada realidade, pode nos ajudar, sobremaneira, no processo de ressignifıcação das especificidades da Educação Especial em nossas sociedades. (SOBRINHO et al., 2015, p. 344).

Nóvoa e Catani (2000) afirmam que, na pesquisa comparada, os pesquisadores devem se posicionar de modo a olhar o mundo como um texto, buscando compreender como os discursos fazem parte dos poderes que partilham e dividem os homens e as sociedades; alimentam situações de dependência e lógicas de discriminação; e constroem maneiras de pensar e de agir que definem nossas relações com o saber e a pesquisa. Com base nessas orientações, pretendemos o constante exercício crítico que permita aos pesquisadores criar categorias férteis na apreensão das peculiaridades e particularidades existentes nos cotidianos investigados.

0 interesse em compreender as políticas de inclusão escolar instituídas no cenário italiano em diálogo com o brasileiro vem se fazendo presente na produção teórica de outros pesquisadores, ganhando destaque os estudos de Meirelles e Baptista (2016) e de Scussiatto (2015). Os primeiros autores citados retomam, em suas pesquisas, a trajetória histórica das políticas de inclusão escolar na Itália, sinalizando que já na década de 1970 o cenário educacional italiano vivenciou mudanças importantes, principalmente com a promulgação da Lei n. ${ }^{\circ}$ 517, de 1977. 
No contexto mundial da luta por direitos sociais, tal movimento se dá no final da década de 1960. Na Itália, fortalece-se um movimento pela desinstitucionalização, ancorada nos princípios da psiquiatria antimaniconial, liderada por Franco Basaglia. Daí advém a busca pelos direitos sociais e educacionais dos alunos com necessidades educativas especiais, colocando a escola comum como espaço-tempo de todos (MEIRELLES; BAPTISTA, 2016).

Os autores problematizam que, entre outras ações, a Itália promoveu o fechamento das classes e escolas especiais, possibilitando o ingresso de todos os alunos no ensino comum, e compôs encaminhamentos importantes para tal ação, ganhando destaque a presença do professor de apoio especializado, o número de alunos por turma não superior a 20 e a oferta de serviços especializados sob a responsabilidade do governo e das redes locais de ensino (regiões e províncias). Entre as políticas voltadas para a inclusão de pessoas com deficiência, os autores também evidenciam ações no campo da saúde, da formação profissional, do trabalho, da garantia de moradia e de transportes públicos acessíveis, além da transposição de possíveis barreiras arquitetônicas e comunicativas, visando compor um plano de atendimento à pessoa desde o seu nascimento até a vida adulta.

No campo educacional, autores como Meirelles, Dainese e Friso (2017, p. 192) também ponderam que

[...] encontramos no contexto italiano um apoio especializado descentralizado, em forma de rede, cujos fios não se restringem ao professor de apoio, mas a todos aqueles presentes no contexto escolar e aos demais envolvidos no percurso de vida da pessoa com deficiência. 0 processo de inclusão escolar se materializa na figura de profissionais envolvidos no percurso da pessoa com deficiência, não possuindo um espaço específico de trabalho individual com o aluno, mas sim prestando apoio ao coletivo de alunos. A engrenagem que possibilita o funcionamento dessa rede de profissionais intersetoriais conta com um contexto político estruturado que possibilita e sustenta os processos de inclusão do país. Nesse caso, os Acordos de Programa por Região e suas respectivas Províncias possuem importante papel, pois é neles que encontramos a descrição da documentação a ser produzida, as figuras profissionais envolvidas e suas respectivas responsabilidades.

Em relação às políticas brasileiras deEducação Especial, os movimentos internacionais por educação para todos e, em especial, pelas pessoas com necessidades educacionais especiais também se presentificam, sendo o Brasil um dos signatários de ordenamentos internacionais, como a Declaração Mundial de Educação para Todos (1990) e a Declaração de Salamanca (1994). Cabe destacar que o país, desde a década de 1960, apontava para a educação desse público, mas a materialização se mostrava tímida e coexistiam dois princípios gerais: a segregação e a integração, quando possivel.

Com a Constituição Federal do Brasil de 1988 e a Lei de Diretrizes e Bases da Educação (Lei n. ${ }^{0}$ 9.394/96), ganham força os princípios pela inclusão na escola comum. Meirelles, Dainese e Friso (2017) apontam avanços no campo educacional (embora com vários desafios a serem superados), demandando, ainda, a composição de políticas mais 
articuladas para sistematização/fortalecimento de redes de apoio intersetoriais e visando ampliar/garantir a qualidade de vida e inclusão social às pessoas com deficiência.

Scussiatto (2015) é outra pesquisadora interessada em promover diálogos sobre as políticas de Educação Especial/inclusão escolar entre a Itália e o Brasil, tomando como ponto de análise as normatizações e a implementação de programas institucionais. No caso brasileiro, destaca a Constituição Federal de 1988 e a Lei de Diretrizes e Bases da Educação Nacional (Lei n. ${ }^{\circ}$ 9.394/96) como duas legislações de grande importância para as políticas de inclusão escolar, pois asseguram o direito de acesso à escola comum com a oferta do atendimento educacional especializado.

A autora pontua, ainda, a Resolução n. ${ }^{\circ}$ 2/2001, que referenda a Educação Especial como modalidade de ensino, rompendo, assim, com sua abordagem substitutiva à escolarização nas escolas comuns, bem como o Decreto n. ${ }^{\circ} 7.611 / 2011$ e a Resolução n. ${ }^{\circ}$ 4/2009, que trazem encaminhamentos para o atendimento educacional especializado em articulação com os currículos escolares, além de orientações acerca do financiamento da Educação Especial. Problematiza também a elaboração da Política Nacional de Educação Especial em uma perspectiva inclusiva, de 2008, que, entre os direcionamentos dados, define quem deverão ser os sujeitos contemplados pelas políticas de Educação Especial. Mais recentemente, o país vem buscando compor políticas em ação para materialização dos princípios gerais da Convenção sobre os Direitos da Pessoa com Deficiência e da Lei Brasileira de Inclusão.

No que se refere à implementação de programas institucionais mediante as legislações supracitadas, Scussiatto (2015) evidencia o Programa de Implementação das Salas de Recursos Multifuncionais (SRM), a Escola Acessível, o Benefício de Prestação Continuada e cursos de capacitação para os professores, ganhando destaque a especialização em atendimento educacional especializado. A autora corrobora o estudo de Meirelles e Baptista (2016), reconhecendo avanços no campo educacional - principalmente quando considerada a historicidade da Educação Especial no Brasil -, mas aponta fragilidades em outras políticas nas áreas da saúde, da assistência social, da mobilidade pública e da acessibilidade.

Quando toma a realidade italiana para análise, retoma a mesma trajetória histórica trazida pelo trabalho de Meirelles e Baptista (2016), evidenciando aportes normativos implementados para as políticas de inclusão escolar - Lei n. ${ }^{\circ}$ 517/1977 e Lei Basaglia, de 1978 - e salientando que a primeira legislação garantiu a inclusão dos estudantes com deficiência nas escolas comuns, bem como a composição de redes de apoio necessárias ao processo, ao passo que a segunda excluiu os manicômios e promoveu a abertura da diversidade para a sociedade italiana. Em 1992, com a Lei n. ${ }^{\circ}$ 104/92, houve a previsão da frequência de todos os alunos, infra ou normodotados intelectualmente, na mesma classe, do maternal à universidade, até os espaços profissionais.

Com base nessas legislações, a autora sinaliza o quanto as políticas de Educação Especial/inclusão escolar buscam potencializar a formação de professores, as relações com os serviços de saúde, educação, assistência social e recursos humanos, bem como a formação profissional e do trabalho para as pessoas público-alvo da Educação Especial, situação que nos permite pensar o quanto o contexto italiano avançou na composição de 
um conjunto de políticas públicas para fazer fomentar a escolarização dos estudantes e projetos sociais voltados à inclusão desses sujeitos na sociedade de maneira mais ampla.

Ao endossarmos as teorizações que buscam compor redes dialógicas entre as políticas de inclusão italianas e as brasileiras, objetivamos, neste texto, promover diálogos entre Sassari e Vitória, para compreender estes questionamentos: que significados/sentidos são atribuídos aos conceitos de inclusão escolar em Sassari e em Vitória? Quem são os sujeitos atendidos pelas políticas de inclusão escolar? Quais são as redes de apoio disponíveis? Quem são os profissionais envolvidos no processo? Que formações esses profissionais possuem? Quais desafios e potencialidades emergem dos dois cenários investigados/ analisados?

No caso de Sassari, tivemos a oportunidade de cartografar as políticas de inclusão escolar por meio de uma investigação qualitativa e colaborativa com a Università degli Studi di Sassari (Uniss), situação que favoreceu a celebração de uma visita técnica ao Instituto Compreensivo Monte Rosello Alto, em maio de 2017. Neste estudo, foram utilizados três grupos focais, que incluíram: professores de apoio (seis), gestores da educação para alunos com necessidades educacionais especiais (cinco) e membros das redes intersetoriais (dez). Para nossas análises, apoiamo-nos em videogravações dos grupos focais e também em documentos oficiais relativos à escolarização de tais sujeitos. As videogravações foram facilitadoras do processo de análise, visto que cada momento pôde ser registrado e revisitado (muitas vezes) pelo grupo de pesquisa, para suas transcrições/análises.

Já no caso de Vitória, trabalhamos com dados coletados por meio de um estudo nacional realizado no transcorrer do ano de 2015, envolvendo 139 professores que atuam no atendimento educacional especializado em dez municípios do estado do Espírito Santo. Os grupos focais foram a ferramenta para a constituição dos dados. Selecionamos dados produzidos por 12 docentes que atuam na Rede Municipal de Vitória, os quais, em cinco encontros de grupos focais, nos ajudaram a entender como eram compostas as políticas de inclusão escolar na referida rede de ensino. Também trabalhamos com videogravações, pelos mesmos motivos expostos quanto ao estudo realizado em Sassari.

\section{Educação Especial em Sassari e em Vitória: traduções,} aproximações e singularidades

Um primeiro ponto de análise diz respeito à composição de aportes normativos. As políticas de inclusão escolar italiana se confrontam com, pelo menos, duas legislações: a Lei n. ${ }^{\circ}$ 104, de 1992 (Legge-quadro per l'assistenza, l'integrazione sociale e idirittidelle persone handicappate), que estabelece normas para assistência, integração social e educação da pessoa com deficiência; e a Lei n. ${ }^{\circ}$ 170, de 2010 (Legge Nuove norme in matéria di disturbi specifici di apprendimento in âmbito scolastico), que versa sobre os processos educacionais dos alunos com distúrbios específicos de aprendizagem no âmbito escolar (MEIRELLES; BAPTISTA, 2016). Tais normativas nacionais se materializam, na região de Sassari, nos apontamentos para diagnóstico, composição de redes de apoio, práticas organizativas e pedagógicas nas escolas e avaliação de acompanhamento dos processos de ensino-aprendizagem dos estudantes. A legislação garante, em todos os territórios locais, 
um Centro de Documentação que, entre outras funções, organiza os diferentes apoios específicos para cada aluno. As leis de 1992 e de 2010 dão conta tanto dos alunos com necessidades educativas especiais em geral, quanto daqueles que apresentam deficiências mais graves. Infere-se que elas sejam suficientes para criarem redes de apoio, tendo em vista que se referem a pessoas que demandam olhares pedagógicos mais diferenciados.

Já a Rede Municipal de Vitória sustenta esse processo na Constituição Federal do Brasil de 1988 e na Lei de Diretrizes e Bases da Educação Nacional, além de buscar respaldo em legislações subsequentes, como a Resolução n. ${ }^{\circ}$ 4/2009 e o Decreto n. ${ }^{\circ}$ $7.611 / 2011$ - que trazem encaminhamentos para a oferta do atendimento educacional especializado e para o financiamento da Educação Especial -, bem como nos princípios orientadores da Convenção sobre Direitos das Pessoas com Deficiência, promulgada em 2007 e transformada em Lei em 2009, com o propósito de "promover, proteger e assegurar o exercício pleno e equitativo de todos os direitos humanos e liberdades fundamentais por todas as pessoas com deficiência e promover o respeito pela sua dignidade inerente" (BRASIL, 2009, art. $1^{\circ}$ ).

Nessa legislação, considera-se como pessoas com deficiência aquelas que apresentam "impedimentos de longo prazo de natureza física, mental, intelectual ou sensorial, os quais, em interação com diversas barreiras, podem obstruir sua participação plena e efetiva na sociedade em igualdades de condições com as demais pessoas” (BRASIL, 2009, art. 1).

Considerando a Convenção sobre Direitos das Pessoas com Deficiência, no Brasil, ganha destaque a Lei n. ${ }^{\circ}$ 13.146/2015, que institui a Lei Brasileira de Inclusão da Pessoa com Deficiência (Estatuto da Pessoa com Deficiência). Tal legislação assegura o pleno exercício dos direitos e das liberdades fundamentais, objetivando processos de inclusão social e o exercício da cidadania, bem como a eliminação de barreiras que venham obstruir a participação efetiva das pessoas com deficiência no contexto social, garantindo condições de igualdade com relação às demais pessoas. No que se refere à Educação, a Lei n. ${ }^{\circ}$ 10.146/2015 estabelece em seu artigo 27 que:

A educação constitui direito da pessoa com deficiência, assegurados sistema educacional inclusivo em todos os níveis e aprendizado ao longo de toda a vida, de forma a alcançar o máximo desenvolvimento possível de seus talentos e habilidades físicas, sensoriais, intelectuais e sociais, segundo suas características, interesses e necessidades de aprendizagem. (BRASIL, 2015, art. 27).

É dever do Estado, da família, da comunidade escolar e da sociedade assegurar educação de qualidade à pessoa com deficiência, colocando-a a salvo de toda forma de violência, negligência e discriminação. (BRASIL, 2015, art. 27, parágrafo único).

Em uma microescala, há as Resoluções n. ${ }^{0 s}$ 06/1999, 07/2008 e 01/2011, que, respectivamente, regulamentam a Educação Infantil, o Ensino Fundamental e a Educação de Jovens e Adultos, trazendo apontamentos sobre as políticas de inclusão nessas etapas e modalidade de ensino (GOBETE, 2014). Cabe ressaltar que esses aportes normativos são influenciados por escalas globais, pois princípios e pressupostos presentes em acordos internacionais (como a Declaração de Jomtien, a Declaração de Salamanca e a Convenção 
dos Direitos das Pessoas com Deficiência) estão incluídos nas normatizações dos dois cenários analisados, respeitadas as singularidades locais.

Outro ponto de análise diz respeito ao conceito inclusão escolar. No contexto italiano, o termo significa acolhimento de todos os sujeitos que trazem singularidades para os cotidianos escolares, seja pela condição de deficiência, ou não. Por isso, há uma legislação que trata de sujeitos com demandas de aprendizagem associadas às deficiências (Lei n. ${ }^{\circ}$ 104, de 1992) e outra que se reporta às pessoas que apresentam distúrbios específicos de aprendizagem: dislexia, disgrafia, disortografia, discalculia e dificuldades linguísticas (Lei n. ${ }^{\circ}$ 170, de 2010).

Vitória parece seguir a tendência nacional, pois, embora no Brasil haja aportes normativos que tratam amplamente da inclusão escolar (educação do campo, educação indígena, educação quilombola, educação de gênero e sexualidade, entre outras) nos cotidianos escolares, quando se fala em inclusão escolar, pensa-se em Educação Especial. Com isso, sujeitos com distúrbios específicos de aprendizagem (à moda italiana) ora são tratados como público-alvo da Educação Especial, ora ficam sem nenhum encaminhamento normativo-político para atendimento às suas necessidades de aprendizagem.

0 terceiro eixo de reflexão reporta-se aos sujeitos contemplados pelas políticas de Educação Especial/inclusão escolar. No caso italiano, utiliza-se o conceito pessoas com necessidades educacionais especiais (trazido pela Declaração de Salamanca) para sinalizar os sujeitos escolares que demandam apoios diferenciados (seja por uma dada deficiência, ou não). 0 conceito necessidades educacionais especiais comporta uma ideia ampla de estudantes com demandas específicas e em processos de escolarização.

0 princípio que orienta esta Estrutura é o de que escolas deveriam acomodar todas as crianças independentemente de suas condições físicas, intelectuais, sociais, emocionais, lingüísticas ou outras. Aquelas deveriam incluir crianças deficientes e super-dotadas, crianças de rua e que trabalham, crianças de origem remota ou de população nômade, crianças pertencentes a minorias lingüísticas, étnicas ou culturais, e crianças de outros grupos desavantajados ou marginalizados. (UNESCO, 1994, p. 3).

Em Vitória, mais uma vez seguindo a moda brasileira, o conceito necessidades educacionais especiais já se fez presente por determinado período; no entanto, no imaginário escolar (e até normativo), esteve atrelado aos sujeitos público-alvo da Educação Especial, conforme podemos perceber na Resolução n. ${ }^{\circ}$ 2/2001, que institui Diretrizes Nacionais para a Educação Especial na Educação Básica.

Consideram-se educandos com necessidades educacionais especiais os que, durante o processo educacional, apresentarem: I - dificuldades acentuadas de aprendizagem ou limitações no processo de desenvolvimento que dificultem o acompanhamento das atividades curriculares, compreendidas em dois grupos: a) aquelas não vinculadas a uma causa orgânica especifica; b) aquelas relacionadas a condições, disfunções, limitações ou deficiências; II - dificuldades de comunicação e sinalização diferenciadas dos demais alunos, demandando a utilização de linguagens e códigos aplicáveis; III - altas habilidades/superdotação, grande facilidade de 
aprendizagem que os leve a dominar rapidamente conceitos, procedimentos e atitudes. (BRASIL, 2001, art. 50 grifos nossos).

Assim, vários estudos (PRIETO, 2009; GARCIA, 2013) problematizaram o quanto tal conceito acabou por promover a produção de estudantes com deficiência - já que aquele que apresentava certa singularidade passava a ser entendido como se tivesse alguma necessidade educacional especial, sendo, portanto, um sujeito com deficiência. Essas problematizações contribuíram na composição de outras definições para os sujeitos contemplados pela Educação Especial, situação expressa na Política Nacional de Educação Especial de 2008, que sinaliza como público-alvo sujeitos que apresentam deficiência, transtornos globais do desenvolvimento e altas habilidades/superdotação.

Se, por um lado, o conceito amplo necessidades educacionais especiais trazia muitos estudantes com necessidades de apoio para a Educação Especial, o fechamento do público-alvo da modalidade de ensino a pessoas com deficiência, transtornos globais do desenvolvimento e altas habilidades/superdotação e a falta de uma política mais direcionada para os demais grupos que demandam apoio acabaram por deixar (diversas vezes) muitos sujeitos com necessidades educacionais especiais (à moda italiana) sem apoio ou atenções diferenciadas aos seus processos de escolarização.

Outro elemento a ser destacado diz respeito à composição de diagnósticos clínicos para encaminhamentos dos alunos às redes de apoio. No caso italiano, reforçam-se as ações intersetoriais entre diferentes profissionais. A busca pela certificação (laudo) envolve família e uma equipe formada por clínicos (neuropsiquiatria), assistentes sociais e educadores (de sala de aula e de apoio) e inclui as áreas cognitiva, neuropsicológica, afetiva, relacional, comunicação linguística e sensorial. Essa avaliação é usada como documento de acompanhamento do aluno ao longo do processo escolar e é revista em diferentes momentos em conselhos de classe. Todos trazem suas contribuições e fazem parte desse grupo.

[...] embora de diferentes setores, todos aqueles que trabalham com as crianças nas diferentes áreas conseguem se encontrar - não é fácil, mas é um movimento que tem se concretizado. 0 bom senso é que determina a participação dos profissionais, mas, de certa maneira, esses são lembrados, convidados. (Transcrição de depoimento de professora de apoio, 2017, tradução nossa).

Os casos não atravessados por uma deficiência são avaliados pelos profissionais das escolas e excepcionalmente, quando necessário, profissionais do setor de saúde e assistência social podem ser chamados para participar do diagnóstico e do acompanhamento dos alunos, garantindo, assim, a introdução de instrumentos de compensação facilitadores dos processos de aprendizagem e a sequência do percurso de formação escolar.

Com a nova legislação, é possivel realizar um trabalho, por exemplo, com um aluno com desvantagem sociocultural. A nova lei regulariza aquilo que já fazíamos. Há como acompanhar e documentar a situação do aluno. Esse documento vai assinado pelo docente de sala de aula e pela família. (Transcrição de depoimento de professora de apoio, 2017, tradução nossa). 
A perspectiva é compensatória, na colocação das professoras:

[...] trabalhar com instrumentos que compensem a dificuldade [...] ideia de trabalhar com mapas conceituais, provas escritas e orais, condições facilitadoras para o aluno evidenciar seus movimentos/progressos, adequando os materiais e a didática às condições e necessidades dos alunos [...] estratégias de ajuda e suporte. (Transcrição de depoimento de professora de apoio, 2017, tradução nossa).

Em Vitória, um ciclo investigativo se inicia na escola pela via das percepções dos professores/pedagogos que acionam as famílias até a composição de diagnósticos clínicos pelos profissionais da área da saúde. As ações intersetoriais ainda são frágeis, ficando as famílias como responsáveis pela busca dos diagnósticos e utilizando serviços públicos de saúde ou privados.

É o professor da sala regular que vai levantar e vai encaminhar para o pedagogo, e o pedagogo vai [...] se comunicar com o professor especialista para fazer a avaliação. Primeiramente, vamos detectar o que aquela criança tem, que não aprende, se é um aluno com deficiência mental, [...] o que está acarretando para aquela criança não aprender, que não consegue alcançar os objetivos. Então este é o passo dado primeiro. Depois chamamos a família e solicitamos que ela leve a criança ao médico para a elaboração do laudo médico. (Transcrição de depoimento de professora de AEE).

As escolas, muitas vezes, como primeira instância promotora desses processos avaliativos, valorizam as faltas, os nãos e as incompletudes nos educandos. Por isso, a avaliação diagnóstica deve ser multirreferencial, para avaliar o estudante, os saberes dos professores, as práticas pedagógicas, os currículos, a avaliação da aprendizagem e as redes de apoio necessárias (JESUS et al., 2015; AGUIAR, 2015).

0 processo avaliativo italiano é sistematizado a partir de uma equipe multiprofissional. Entre nós, brasileiros, inicialmente esse processo se dá na escola. Na Itália, parece predominar um olhar mais clínico, principalmente a partir da Lei n. ${ }^{0}$ 170/2010. Já no Brasil, as unidades escolares apresentam certa dependência para com os diagnósticos clínicos, mas, mediante as fragilidades encontradas nos sistemas de saúde e assistência social, cabe a elas promover uma avaliação pedagógica para encaminhamento dos alunos aos serviços de apoio e inclusão no censo escolar, conforme orienta a Nota Técnica 04/2014/MEC/ SECADI/DPEE (BRASIL, 2014).

No que se refere aos apoios pedagógicos nas escolas comuns, Sassari conta com professores de apoio aos alunos que apresentam certificação (diagnóstico). Para os casos mais sérios, é definido um professor de apoio por aluno, podendo esse profissional atuar com até três alunos. Para os outros casos - desvantagem socioeconômica, diversidade cultural, dificuldade relacional-comportamental -, via de regra, não é disponibilizado um professor de apoio, mas este atua em assessoria a planejamento educacional específico que atenda às necessidades dos alunos, situação definida a partir da Lei n. ${ }^{\circ}$ 170/2010.

Além desse docente, a escola conta com o assistente, que é um educador que se preocupa com a autonomia pessoal e operativa e acompanha os alunos que demandam 
maior apoio. Em uma escola que pudemos conhecer, por exemplo, 40 alunos são certificados (possuem laudos), dos quais 27 têm assistentes, e isso depende das condições financeiras do sistema educacional. Esse profissional não atua no mesmo momento em que atua o professor de apoio.

Em Vitória também há contratações de professores com certificação nas diferentes áreas da Educação Especial. Entretanto, há grande dependência dos professores da sala de aula comum quanto à contratação de estagiários como apoio pedagógico aos estudantes. Muitas vezes, tais contratações são condições impostas pelas escolas para a permanência dos estudantes em sala de aula. Em caso de estudantes que demandam apoio para locomoção, alimentação e higienização, a rede de ensino conta com o trabalho de cuidadores.

A composição de redes de apoio se coloca como uma ação que, se satisfeita, pode ampliar os processos de apropriação do conhecimento pelos discentes; garantir maior envolvimento nas ações planejadas e desenvolvidas pelos professores; e oferecer possibilidades de esses profissionais se subjetivarem como também corresponsáveis pelos alunos. Trata-se de uma questão complexa, pois a rede só faz sentido quando há a participação de todos, e não somente de um grupo que solitariamente tende a se responsabilizar sozinho pelo aluno.

0 trabalho em rede estimula seus integrantes a participar da experiência de seus outros componentes. Esse estímulo de convivência produz dois movimentos: o de auto-conhecimento e o de participação mais ativa e solidária na comunidade. Esses movimentos são complementares e indissociáveis, criando relações que provocam mudanças numa cultura amparada em vínculos de dependência e na tradição hierárquica que tanto marcaram as ações nos serviços públicos brasileiros. Redes abertas permitem que as informações possam ser compartilhadas por todos, sem canais reservados. Permitem, portanto, que se favoreça a formação de uma cultura da participação, da cooperação, da co-responsabilidade, mas também da autonomia. (HOFFMANN et al., 2000, p. 22).

Ainda no âmbito da organização do trabalho pedagógico, no contexto italiano existe um Plano Educacional Individualizado (PEI), por sua vez elaborado pela equipe escolar em conjunto com profissionais da área da Assistência Social e Clínica. O PEI inclui a descrição do caso, um planejamento das ações educacionais para o ano letivo e, se necessário, a descrição de uma didática específica.

Para os outros casos - desvantagem socioeconômica, diversidade cultural, dificuldade relacional-comportamental -, compete à escola elaborar um Plano Didático Personalizado (PDP) a ser constituído pelo professor de sala de aula e pelos gestores escolares. Tais casos, recentemente, podem contar com as ações do professor especializado em alguns momentos/aspectos de sua escolarização, conforme a Lei n. ${ }^{\circ}$ 170/2010.

Em Vitória, também há iniciativas para a organização de um Plano de Trabalho Pedagógico (PTP), denominação que o documento ganha no cenário capixaba. Há orientações para que esse plano seja constituído a cada trimestre letivo, envolvendo professores da sala de aula comum, pedagogos e profissionais do atendimento educacional especializado. Não há profissionais da área da saúde e assistência social envolvidos nessa elaboração. 
Temos o documento "Plano de Trabalho Pedagógico". Quem traça, na verdade, o que vai ser ensinado é o próprio professor da sala de recurso. Sempre tentamos envolver os professores regulares. E "o quê", a gente busca os conteúdos na proposta da escola. Utilizamos os materiais direcionados para a própria sala de recursos, que são os jogos, o computador. Procuramos materiais para estar trabalhando com eles a partir das necessidades que eles precisam. (Transcrição de depoimento de professora).

0 plano deve tomar como ponto de apoio o currículo da turma e expressar as ações do atendimento educacional especializado como forma de envolvimento dos estudantes nas ações planejadas e desenvolvidas pelos professores na sala de aula comum, bem como no atendimento educacional especializado (contraturno). Nem de longe esse plano é organizado sem grandes enfrentamentos/barreiras, pois, no imaginário escolar, os docentes de Educação Especial e/ou os demais serviços de apoio são (muitas vezes) os únicos responsáveis pelos estudantes.

Mediante a fragilidade (até mesmo inexistência) de normativas e políticas dirigidas para outros grupos de estudantes que demandam apoios diferenciados, a Política Nacional de Educação Especial pontua que, nos casos de transtornos funcionais específicos, a Educação Especial atua articuladamente com o ensino comum, orientando o atendimento desses estudantes (BRASIL, 2008). Diferentemente do contexto italiano - que opera com Plano Didático Personalizado (PDP) -, no cenário brasileiro não há nenhum instrumento que sistematize esse trabalho, sendo os professores orientados a realizar atividades pedagógicas diferenciadas com esses discentes.

Além da elaboração do PEI e do PDP, em Sassari, e do PTP, em Vitória, as duas realidades apostam no trabalho colaborativo - professores regulares e de apoio trabalhando em conjunto em sala de aula. No caso italiano, essa experiência colaborativa se encontra mais consolidada, conforme podemos perceber na narrativa de uma docente: "Ele é um aluno de uma classe, não do professor de apoio" (Transcrição de depoimento de professora de apoio, 2017, tradução nossa).

A colaboração se dá no trabalho com o aluno em classe, o objetivo é sempre trabalhar o que está sendo tratado na aula. 0 trabalho é com os colegas [...] a riqueza na diversidade, a turma se sensibiliza por ter um colega com necessidades especiais. (Transcrição de depoimento de professora de apoio, 2017, tradução nossa).

Em Vitória, o trabalho colaborativo é amplamente negociado, tendo em vista a resistência de alguns professores que ainda defendem que os alunos devam ser atendidos fora da sala de aula comum, conforme narra uma docente capixaba: "os professores não se sentem responsáveis pelos alunos. Dizem: seu aluno chegou. Professores de Educação Especial e os estagiários, no imaginário escolar, ainda são os responsáveis pelos alunos" (Transcrição de depoimento de professora). Além do trabalho colaborativo, os profissionais de apoio realizam o atendimento educacional especializado no contraturno.

Em relação à avaliação da aprendizagem, em Sassari o processo focaliza os pontos de força do aluno e é diretamente associado aos objetivos estabelecidos no início do ano. 
A avaliação escolar é quadrimestral. Ao final desse período, é usado um formulário de avaliação específico para alunos com necessidades educacionais especiais. No segundo quadrimestre (em junho), é realizada uma avaliação final. Essa segunda avaliação diz respeito, também, ao que o aluno deve fazer no ano seguinte - isso é fundamental quando o aluno muda de escola, e os instrumentos são estandardizados para a área. Há um monitoramento, não é algo fixo. É

[...] algo que vai crescendo, aposta-se nas mudanças e, quando não se alcançam resultados positivos, a metodologia é mudada, a preocupação não está na nota/pontuação final, mas no desenvolvimento da criança. (Transcrição de depoimento de professora de apoio, 2017, tradução nossa).

Já em Vitória, os estudantes são avaliados a cada trimestre, por meio de relatórios. Busca-se assegurar "avaliação contínua e cumulativa do desempenho do aluno, com prevalência dos aspectos qualitativos sobre os quantitativos e dos resultados ao longo do período sobre os de eventuais provas finais" (BRASIL, 1996, art. 24, inciso 4, letra a). Mesmo assim, a avaliação da aprendizagem em Sassari e em Vitória é permeada de desafios, pois o acesso à apropriação do conhecimento se apresenta como um desafio a ser superado pelas duas redes de ensino, situação que implica os processos de avaliação da aprendizagem, pois, se não se garante o direito de aprender, como avaliar esse processo?

Talvez o maior dilema se coloque quando [os professores] pensam a avaliação do rendimento escolar. Aprovação, reprovação, atribuição de conceitos e notas, terminalidade específica e adaptações de instrumentos avaliativos ainda desafiam a inventividade dos profissionais da Educação que se colocam a responsabilidade de pensar a Educação Especial. (JESUS et al., 2015, p. 37).

Sobre a formação docente, em Sassari, a formação exigida para o professor de apoio é a certificação em curso de nível superior na área da Educação, mais uma certificação específica nas diferentes áreas da Educação Especial. Trata-se de formação polivalente, ou seja, generalista. Segue-se a tal formação um exame nacional. Essa formação específica tem a duração média de um ano, e as docentes necessitam, ao longo do trabalho, realizar outras formações mais específicas.

Já a formação do assistente é diversa, não precisando ser graduado, mas possuir um curso específico para exercer a tarefa de assistente. Os professores de apoio, às vezes, preparam atividades para que os assistentes desenvolvam. Vale ressaltar que a formação continuada é paga pelos professores e que, algumas vezes, o poder público disponibiliza formações; no entanto, as docentes argumentam que são poucas e com carga horária reduzida.

No caso de Vitória, também é requisitada a formação em nível superior, embora a Lei de Diretrizes e Bases da Educação Nacional (Lei n. ${ }^{\circ}$ 9.394/96) assegure a docência para a Educação Infantil e o Ensino Fundamental I aos profissionais com formação em nível médio na modalidade Normal. Há docentes que cursaram Pedagogia, acrescida da habilitação em Educação Especial; outros possuem graduações diversas, somadas a cursos de especialização em Educação Especial; e há uma grande maioria com curso superior e cursos de capacitação de 120 horas. No que tange à formação continuada, há investimento 
por parte tanto dos docentes quanto da própria rede de ensino, inclusive por meio de parcerias com a universidade e outras instâncias formativas.

Sobre a carga horária de trabalho docente, no cenário italiano os docentes de sala comum possuem 40 horas de trabalho semanal, enquanto o professor de apoio tem uma carga horária de 24 horas semanais. Já em Vitória, os professores de sala de aula comum e do atendimento educacional especializado possuem, em sua maioria, 25 horas de trabalho, entre as quais 20 horas são cumpridas em sala de aula e 5 são dedicadas ao planejamento do trabalho pedagógico. Muitos docentes atuam até em três turnos (em escolas/redes de ensino diversas), situação que traz uma grande sobrecarga de trabalho, implicando, consequentemente, as atividades que realizam com os estudantes.

Oliveira (2008), ao direcionar seus estudos para as condições de trabalho docente, problematiza que o processo de intensificação desse trabalho provoca degradação em termos não só de qualidade da atividade, mas também de qualidade do trabalho e da vida do professor. Lidando com a falta de tempo, os trabalhadores limitam a atividade em suas dimensões centrais, ou seja, manutenção do controle da turma e cumprimento de dispositivos regulatórios. 0 sofrimento no trabalho, associado ao adoecimento, está sempre ligado a um conflito entre a vontade de bem fazer o seu trabalho, de acordo com as novas regras implícitas da profissão, e a pressão que os leva a certas regras, para aumentar a sua produtividade.

\section{Considerações finais}

Com o estudo, podemos perceber que acordos internacionais impactaram a implementação de políticas públicas nos dois cenários analisados, pois ambos foram compondo ações voltadas à escolarização de sujeitos que trazem a diferença significativa para as escolas comuns. Na implementação dessas políticas, há que se considerar que a proposta inclusiva na Itália data de 1977 e se coloca numa perspectiva de educação para todos, ou seja, rompe com qualquer possibilidade de segregação e radicaliza a defesa da escola comum como lócus de escolarização. Já em Vitória, essas políticas ganham sustentação no início da década de 1990, ainda por meio de um processo que mesclava a inclusão na escola comum e a presença de instituições especializadas com abordagens substitutivas (GOBETE, 2014). Trata-se de um movimento que considera as temporalidades possíveis nos diferentes territórios que apresentavam condições histórico-culturais diferenciadas. É somente no final dos anos 1990 e no início dos anos 2000 que se apresenta uma proposta mais radical de inclusão escolar.

Assim, o estudo considera o longo percurso já percorrido pelas políticas italianas em razão da constituição de escolas inclusivas, bem como a processualidade desse fenômeno no contexto capixaba; contudo, permite-nos entender que tanto Sassari quanto Vitória produzem movimentos para que estudantes com necessidades educacionais especiais (à moda italiana) ou com deficiência, transtornos globais do desenvolvimento e altas habilidades/superdotação (à moda brasileira) tenham o direito de aprender.

Evidencia-se que políticas públicas existem nos cenários analisados e que muitas das políticas italianas se aproximam das brasileiras, é lógico, respeitando a processualidade de 
cada um desses cenários. Há movimentos e tentativas para assumir a diferença humana como condição intrínseca e constitutiva do humano e, conforme diria Boaventura de Sousa Santos (2008), para desnaturalizar a assunção da diferença como algo que produz sujeitos residuais, inferiores e lançados para um lado abissal das escolas/sociedades.

A constituição deste estudo nos permite analisar o quanto a realidade italiana e a brasileira podem aprender em diálogo uma com a outra, pois, considerando as diferenças históricas, econômicas, políticas, estruturais e educacionais, podemos dizer que há avanços na matrícula dos estudantes na escola comum, composição de redes de apoio para que eles permaneçam e um conjunto de preocupações e tentativas para garantir o acesso ao conhecimento sistematizado. Conforme anunciado no transcurso do texto, trabalhar com a pesquisa comparada em Educação não significa anunciar que uma determinada realidade está melhor que a outra, mas permitir que uma se traduza na outra (sem canibalização), pois esse processo pressupõe a busca pela inteligibilidade, sem destruir a diversidade (SANTOS, 2008).

\section{Referências}

AGUIAR, Ana Marta Bianchi. Calcanhar de Aquiles: a avaliação do aluno com deficiência intelectual no contexto escolar. 2015. Tese (Doutorado em Educação) - Programa de Pós-Graduação em Educação, Universidade Federal do Espírito Santo, Vitória, 2015.

ARROYO, Miguel Gonzalez. Outros sujeitos, outras pedagogias. Petrópolis: Vozes, 2014.

BANCO MUNDIAL. Relatório mundial sobre a deficiência: Organização Mundial da Saúde; 0 Banco Mundial. Trad. Lexicus Serviços Linguísticos. São Paulo: SEDPcD, 2012. 334 p.

BRASIL. Decreto n. ${ }^{\circ}$ 6.949. Promulga a Convenção Internacional das Pessoas com Deficiência e seu protocolo facultativo, assinados em Nova York, em 30 de março de 2007. Diário Oficial da União, Brasília, DF, Seção 1E, 25 ago. 2009.

BRASIL. Lei n. ${ }^{\circ}$ 9.394, de 20 de dezembro de 1996. Estabelece as diretrizes e bases da educação nacional. Diário Oficial da União, Brasília, DF, Seção 1, 23 dez. 1996.

BRASIL. Lei no. 13.146. Institui a lei brasileira da pessoa com deficiência (Estatuto da Pessoa com Deficiência). Diário Oficial da União, Brasília, DF, Seção 1E, 6 jul. 2015.

BRASIL. Resolução CNE/CEB n. ${ }^{\circ}$ 2. Institui diretrizes nacionais para a educação especial da educação básica. Diário Oficial da União, Brasília, DF, Seção 1E, 14 set. 2001.

BRASIL, Ministério da Educação. Política pública de educação especial na perspectiva da educação inclusiva. Brasília, DF: MEC, 2008.

BRASIL. Ministério da Educação. Secretaria de Educação Continuada, Alfabetização, Diversidade e Inclusão. Nota técnica nº4 / 2014 / MEC / SECADI / DPEE, de 23 de janeiro de 2014. Brasília, DF: MEC, 2014. Orientação quanto a documentos comprobatórios do cadastro de alunos com deficiência, transtornos globais do desenvolvimento e altas habilidades/superdotação no censo escolar. 
FRANCO, Maria Ciavatta. Quando nós somos o outro: questões teórico-metodológicas sobre os estudos comparados. Educação \& Sociedade, Campinas, v. 21, n. 72, p. 197-230, ago. 2000.

GARCIA, Rosalba Maria Cardoso. Política de educação especial na perspectiva inclusiva e a formação docente no Brasil. Revista Brasileira de Educação, Rio de Janeiro, v. 18, n. 52, p. 101-119, jan./mar. 2013.

GOBETE, Girlene. Educação especial no município de Vitória/ES no período de 1989 a 2012: políticas e direito à educação. 2014. Tese (Doutorado em Educação) - Programa de Pós-Graduação em Educação, Universidade Federal do Espírito Santo, Vitória, 2014.

HOFFMANN, Cristina et al. Reflexões sobre rede de atendimento à criança e ao adolescente. Ponta Grossa: UEPG, 2000. Núcleo de Estudos sobre a Questão da Criança e do Adolescente.

JESUS, Denise Meirelles de et al. Avaliação e educação especial: diálogos sobre diagnóstico, planejamento e rendimento escolar nas salas de recursos multifuncionais. In: JESUS, Denise Meyrelles de; GONÇALVES, Agda Felipe Silva (Org.). Formação, práticas pedagógicas e inclusão escolar no Observatório Estadual de Educação Especial. v. 1. 1. ed. São Carlos: Marquezine \& Manzini; ABPEE, 2015. p. 93-114.

MARCONDES, Martha Aparecida Santana. Educação comparada: perspectivas e investigações. Eccos, São Paulo, v. 7, n. 1, p. 139-153, jun. 2005.

MEIRELLES, Melina Chassot Benincasa; BAPTISTA, Claudio Roberto. Os processos de inclusão escolar na Itália e a educação infantil no contexto de Bologna. In: REUNIÃO CIENTíFICA REGIONAL DA ANPED EDUCAÇÃO, MOVIMENTOS SOCIAIS E POLÍTICAS GOVERNAMENTAIS, 2016, Curitiba. Anais... v. 1. Curitiba: Anped, 2016. p. 1-15.

MEIRELLES, Melina Chassot Benincasa; DAINESE, Roberto; FRISO, Valeria. A educação especial no contexto italiano: 0 projeto de vida, da escola à vida adulta. Revista Educação Especial, Santa Maria, v. 30, n. 57, p. 189-201, jan./abr. 2017.

NÓVOA, Antonio; CATANI, Denice B. Estudos comparados sobre a escola: Portugal e Brasil (séculos XIX e XX). Rio de Janeiro: [s. n.], 2000. Texto aprovado para ser apresentado no I Congresso Brasileiro de História da Educação.

OLIVEIRA, Dalila Andrade. Os trabalhadores docentes no contexto de nova regulação educativa: análise da realidade brasileira. In: SEMINARIO REDESTRADO NUEVAS REGULACIONES EN AMÉRICA LATINA, 7., 2008, Buenos Aires. Anais... v. 1. Buenos Aires: Redestrado, 2008. p. 1-17. 1 CD-ROM.

PRIET0, Rosângela Gavioli. A educação especial em municípios paulistas: histórias singulares ou tendência unificadora? In: BAPTISTA, Cláudio Roberto; JESUS, Denise Meyrelles de (Org.). Avanços em políticas de inclusão: 0 contexto da educação especial no Brasil e em outros países. Porto Alegre: Mediação, 2009. p. 57-78.

REZENDE, Valéria M.; ISOBE, Rogéria Moreira R.; MOREIRA, Fernanda Arantes. Investigação comparada em educação: aspectos teóricos e metodológicos. Revista Educação e Políticas em Debate, Uberlândia, v. 2, n. 1, p. 229-248, jan./jul. 2013. 
SANTOS, Boaventura de Sousa. A filosofia à venda, a douta ignorância e a aposta de Pascal. Revista Crítica de Ciências Sociais, Coimbra, n. 80, p. 11-43, mar. 2008.

SCUSSIATTO, Caroline Carminatti. Inclusão: percursos e experiências educacionais no Brasil e na Itália. Informática na Educação, Porto Alegre, v. 18, n. 2, p. 19-37, jul./dez. 2015.

SOBRINHO, Reginaldo Celio et al. Estudo comparado internacional: contribuições para o campo da educação especial. Revista Brasileira de Educação Especial, Marília, v. 21, n. 4, p. 335-348, out./dez. 2015.

UNESCO - Organização das Nações Unidas para a Educação, a Ciência e a Cultura. Declaração de Salamanca e enquadramento da ação: necessidades educacionais especiais. Salamanca: Unesco, 1994.

UNESCO - Organização das Nações Unidas para a Educação, a Ciência e a Cultura. Declaração Mundial sobre Educação para Todos. Tailândia: Unesco, 1990.

Recebido em: 25.01.2018

Revisões em: 02.05.2018

Aprovado em: 13.08.2018

Denise Meyrelles de Jesus é licenciada em pedagogia pela Universidade Federal do Espírito Santo (UFES), mestra em educação pela University of lowa, doutora em psicologia da educação pela University of California e pós-doutora em educação especial pela Universidade de São Paulo (USP) e em educação pela Universidade Federal do Rio Grande do Sul(UFRS). É professora titular da UFES. Tem experiência na área da educação, com ênfase em educação especial.

Alexandro Braga Vieira é licenciado em letras e em pedagogia, mestre, doutor e pós-doutor em educação pela Universidade Federal do Espírito Santo (UFES). É professor do Programa de Pós-Graduação em Ensino, Educação Básica e Formação de Professores, bem como coordenador do Programa de Pós-Graduação de Mestrado Profissional em Educação, ambos na UFES. Tem experiência na área da educação, com ênfase em educação especial.

Lorrayne Hewellen Cristino Ribeiro é licenciada em pedagogia e mestranda do Programa de Pós-Graduação em Educação da Universidade Federal do Espírito Santo (UFES).

Renata Santos Venturini é licenciada em pedagogia e mestranda do Programa de PósGraduação em Educação da Universidade Federal do Espírito Santo (UFES). 